https://doi.org/10.48009/1_iis_2006_144-149

\title{
IDENTIFYING NEW PEDAGOGICAL OPTIONS FOR TEACHING INFORMATION SYSTEMS IN BUSINESS IN A LARGE CLASSROOM
}

\author{
Amy D. Bauer, IS, University of Wisconsin - Eau Claire, bauerad@uwec.edu \\ Thomas S.E. Hilton, IS, University of Wisconsin - Eau Claire, hiltonts@ uwec.edu
}

\begin{abstract}
In response to growing signs of irrelevancy, a redesigned pilot course of an introductory information systems course at a midsized public university was tested. Course content was revised to emphasize ways information technology can support business processes. Presentation techniques were modified to increase student engagement with other students, both in the class and in the information systems major. Student responses from the pilot implementation were encouraging.
\end{abstract}

Keywords: AACSB Core, IS Education, Introductory IS Course, Information Systems (IS)

\section{INTRODUCTION}

AACSB-accredited business schools are to educate their undergraduate students in a common body of knowledge, one component of which is information technology and systems [2].

As identified in the 2002 Information Systems (IS) Model Curriculum, developed with support from three leading IS industry organizations (AIS, ACM and AITP), two core IS courses should be provided for all business students. The first course focuses on increasing student skills with end-user productivity tools, while the second focuses on IS concepts and terminology such as systems theory, decision making, and the role of IS in business [5].

The learning goals identified for these two core IS courses have been combined and reduced into a single core IS course provided at the mid-sized public university discussed in this paper. The aim of this core IS course has traditionally been to teach students to apply information systems vocabulary and concepts to business and to increase skills with productivity tools such as MS Excel.

Methods of teaching this course have often centered on lectures in large sections (e.g., 100 or more students per section). However, a number of signals indicate the status quo must change: faculty perception of student skills, student evaluation data, low content retention, dropping IS enrollments and declining interest in IS among women.

Declining enrollments in technology programs is a trend seen at educational institutions across the country. Enrollments have dropped as much as 50\% from 2001-2004, according to Robert Baskerville, Georgia State University [3].

Low enrollments are paired with missed opportunity, as America's Career InfoNet reports 5 of the 10 fastest growing jobs, requiring a bachelor's degree or higher, are in the IS field [1]. The opportunities in IS are magnified by the Bureau of Labor Statistics. Overall, the Bureau estimates growth of IS professional and related occupations to grow as much as $45 \%$ by 2014 [4]. Information for specific IS careers is included in Table 1.

Table 1. Bureau of Labor Statistics, Estimated Job Growth Between 2004 and 2014 [4].

\begin{tabular}{|l|c|}
\hline IS Professional and related occupations & $\begin{array}{c}\text { \% of } \\
\text { Change }\end{array}$ \\
\hline $\begin{array}{l}\text { Computer and information scientists, } \\
\text { research }\end{array}$ & 35.6 \\
\hline Computer programmers & 10.6 \\
\hline Computer software engineers, applications & 62.7 \\
\hline $\begin{array}{l}\text { Computer software engineers, systems } \\
\text { software }\end{array}$ & 62.2 \\
\hline Computer support specialists & 35.6 \\
\hline Computer systems analysts & 49.2 \\
\hline Database administrators & 56.4 \\
\hline $\begin{array}{l}\text { Network and computer systems } \\
\text { administrators }\end{array}$ & 58.1 \\
\hline $\begin{array}{l}\text { Network systems and data communications } \\
\text { analysts }\end{array}$ & 81.5 \\
\hline Computer specialists, all other & 35.6 \\
\hline Computer hardware engineers & 37.3 \\
\hline
\end{tabular}

Low content retention and course satisfaction in the core IS course in question are believed to negatively impact IS major enrollments. The lead instructor is hopeful that improving student engagement, a 
requirement of AACSB-accredited schools, is one solution to improve the trends [2].

To increase engagement and ensure continued service to the business college at large, a decision was made to create a redesigned pilot section of the core IS course in the spring of 2006.

To identify specific improvements to address in the course, past core IS course students were surveyed and interviewed. Also, non-IS business faculty were surveyed. Based on the results, the pilot features new activities, presentation formats, case studies and more. Upon completion of the pilot course, openended data was collected to understand student perceptions of the changes.

This paper reports the survey and interview results, the innovations in content and pedagogy implemented in the pilot section of the core IS course and the effects emerging from them.

\section{RESEARCH}

Low content retention, low levels of course satisfaction and a lack of growth in IS major enrollments are trends being experienced in the core IS course, just as they are being experienced by many other universities. A lack of interaction and engaging activities during lecture, as well as disconnect between self-study assignments and in-class content are believed to be the main drivers for the trends in the core IS course at the university discussed in this paper.

To support this hypothesis, the following comments from course evaluations were provided by students who experienced the "traditional" core IS course in the fall of 2005 :

- "Try not to have full hour and 15 minutes of straight lecture - definitions/terms, etc. Gets very boring."

- "Since everything is pretty much on the PowerPoints it doesn't always seem worth it to go to class."

- “...make it more interesting (easier to understand)."

- "Material is fairly boring, but I'm not sure much can be done about that."

- "More in-class activities to stimulate students. Material can be very dry at times. Activities would help increase focus."

These comments are a snapshot of responses received from all 240 students in the fall of 2005. These students completed a standard course evaluation used across the business school. The data in Figures 1 and 2 reflect additional information collected from these evaluations.

As demonstrated in Figure 1, over half of the students felt attending class did not have an impact on their level of learning. Yet, as shown in Figure 2, over two-thirds felt the instructor required the students to think.

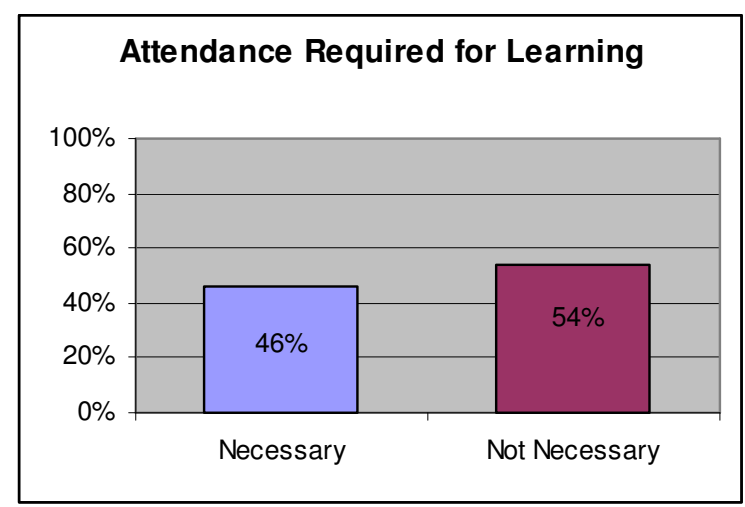

Figure 1. Is Class Attendance Required to Learn?

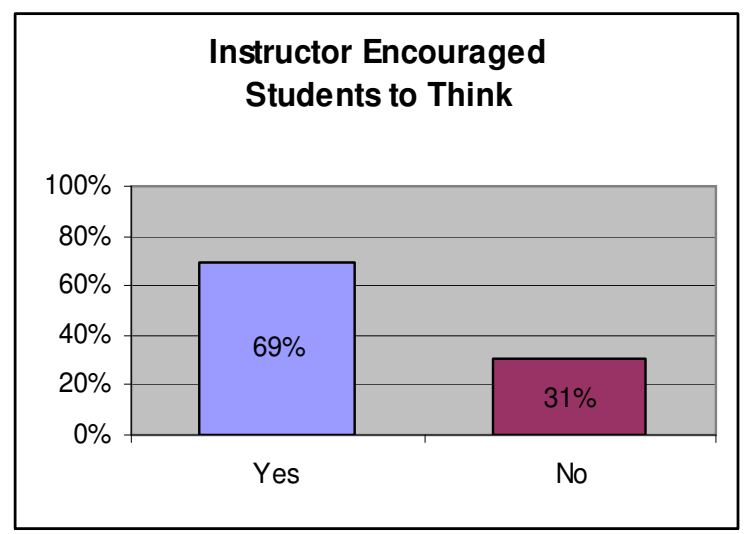

Figure 2. Does the Instructor Encourage Students to Think?

The disconnect between the need to attend class and the requirement to think may be a result of the amount of self-study MS Excel work completed outside of the classroom. Approximately $30 \%$ of the student grade is based on work the students complete with minimal or no direction or assistance from the instructor.

Even though Figure 2 demonstrates a large number of students that are encouraged to think, this result is of concern to the instructor as almost one-third of the students identified themselves as not being challenged in the course. 
Students from the fall of 2005 also indicated they enjoyed completing review activities during class sessions, working through in-class activities and having course content available in organized PowerPoint presentations. These practices are being retained in the revised, pilot course.

- "I liked the reviews at the beginning of class because it helped me to better understand the material."

- "I think in-class activities and reviews are very effective. Also, examples used outside of the PowerPoints helped me."

- "I liked the PowerPoints to follow along with the class discussion."

- "Review before class of the previous day's topics and everything on D2L, especially the study guides."

To better understand the perception of the core IS course, Junior and Senior business students who completed the course earlier in their program were interviewed. These students identified the following common trends: the lack of continuity across course content, the overwhelming amount of concepts and terms and minimal long-term retention of course content. Students discussed the need for hands-on activities to increase the level of understanding and retention. They also encouraged the faculty to reduce the overall amount of content for the course. One student noted, "That course needs to be changed! There was so much information and none of it seemed to relate. Other than Excel, I don't remember anything from that course." This comment is consistent with most others, with Excel being a key learning.

With the traditional course structure, Excel tutorials are completed as self-study activities with minimal or no support provided. This leads to an assumption that students learn the most from the Excel tutorials-not from the in-class lectures, which include various IS terms and concepts.

After reviewing the data from the students in the fall of 2005, and the interviews of Junior and Senior students, four major concerns were identified:

- difficulty integrating the mass of IS vocabulary and concepts into a cohesive structure,

- difficulty seeing the relevance of IS concepts to business concepts,

- a misperception that IS is an arcane discipline with few social opportunities, and

- a misperception that IS career opportunities are declining in number.
To obtain a different perspective, the business faculty was also approached. With regular student interaction during upper-level core coursework, student organizations and advising, this group was asked to provide input regarding their perception of the core IS course.

All business faculty were presented with a survey consisting of two components; the first rated the "importance of each IS core course objective to student success in the business courses they teach," the second rated the importance for students to know a series of skills used with productivity tools and when faculty felt the students should learn the skills.

Ten out of 40 (25\%) faculty responded to the survey, yielding a list of items perceived as important in the IS core course, mostly in end-user productivity tools and skills. The main finding was a perceived disconnect between IS objectives and those of other business disciplines. Specific preferences expressed by the faculty include the following:

- Explain how information systems are used to solve problems and make decisions

- Explain the impact of information systems on business activities

- Appreciate ethical, moral, and legal duties related to intellectual property, information access, information privacy, and information accuracy.

- Identify and apply personal productivity tools to help solve business problems.

- Utilize learning management software

- Format and manage documents

- Create, add formulas, add charts, and format spreadsheets

- Format, use master slides, graphics and multimedia in presentations

- Communicate through e-mail and shared calendar

- Eliminate from this core IS course any reviews of IS career opportunities, IS project processes and documentation procedures, advanced Excel functions, database design and development, wired and wireless networks, and PC hardware purchases.

\section{PILOT STUDY COURSE}

Working within significant funding constraints, we redesigned the core IS course to improve student motivation, content retention, and interest in IS as a major among both men and women. Changes include the following: 
Restructuring course objectives to focus and organize student learning. In recent years, 20 objectives were included in the course syllabus. These objectives have been reduced to five key ideas. The objectives used to focus the redesigned course include the following:

1. Identify and explain the components of an information system.

2. Explain the impact of information systems on business activities.

3. Apply a common project process to the development of systems.

4. Demonstrate the use of information systems to solve problems and make decisions.

5. Differentiate information systems concepts and vocabulary.

Initiating a lecture-lab format to promote experiential learning and student interaction. Within the redesigned course, classes met for 50 minutes, three days a week, with two classes being lecture format and one being dedicated for small group labs. Previously, classes met for one hour and fifteen minutes, twice a week.

Using team projects to promote social interaction and reinforce lecture-based content. Lab activities included team projects and activities; students worked together to build a decision support application in Excel, they also worked in teams to develop PC hardware and software purchase recommendations, based on various business requirements.

Implementing a personal productivity pre- and posttest to support in-class instruction. SAM 2003 Assessment and Training from Thomson/Course Technology was used to facilitate the pre- and posttests. These tests were conducted in the first and last week of class, respectively. The tests focused solely on Excel tasks and skills. The future intent is to assess student skills across productivity tools and provide relevant self-study training for students to fulfill any deficiencies that exist.

Inviting guest speakers from industry to address career options and topics in IS. No guest speakers presented in the spring pilot. However, speakers presented in the traditional sections and maintained a high level of student interest and generated excellent questions in support of course content. Student feedback regarding the increased ability to understand course content due to guest presentations drives continued utilization.
Having senior IS students as lab instructors. Three senior students developed and facilitated activities for all lab sessions. The seniors received course credit for their capstone IS course, as they practiced skills needed to communicate technology-based information with others who did not have their background With over 240 students in a semester, knowledgeable lab instructors and small group support is critical to the success of the lab component.

Using case studies in both lecture and lab. A single storyline was used throughout the lab activities. This engaged the students in supporting a single company through a series of scenarios. These scenarios complemented the content being covered during lecture.

Using a student response system in the lecture to increase student involvement. Students answered review questions in writing, discussed them in pairs, or answered out loud. The instructors' ability to receive real-time feedback regarding student comprehension during reviews and lectures was critical. Although we considered implementing a technology-based student response system (e.g., clickers), the changing technology and the inconsistent reliability of the options currently on the market dissuaded us and we retained the low-tech alternative.

\section{DISCUSSION}

Thirty students, approximately 50\% working toward acceptance to the college of business and 50\% taking the course as an elective or a required course for a non-business major, experienced the redesigned, pilot-study, core IS course. This group benefited from small group labs, team-based interaction and in-class support provided by the seniors. As this paper was written, data from the standard course evaluations was not available. However, student feedback demonstrated an increased level of satisfaction with the format of the redesigned course.

In May 2006, an anonymous, open-ended questionnaire was made available to two traditional large group sections and the pilot section of the core IS course. Twenty-four $(9.84 \%)$ responses were submitted by students in the traditional sections, with $22(73.3 \%)$ responses from the pilot course. Figures 3-5 demonstrate the differences in perception between the traditional and pilot sections.

When asked about the labs and assignments they learned the most from (Figure 3), the traditional 
section repeatedly identified the self-study Excel assignments. Students in the pilot completed the same Excel assignments; however, only $18 \%$ of this group identified Excel as the part they learned the most from. In their responses, the pilot students drew a greater emphasis to the other assignments and activities completed during the course.

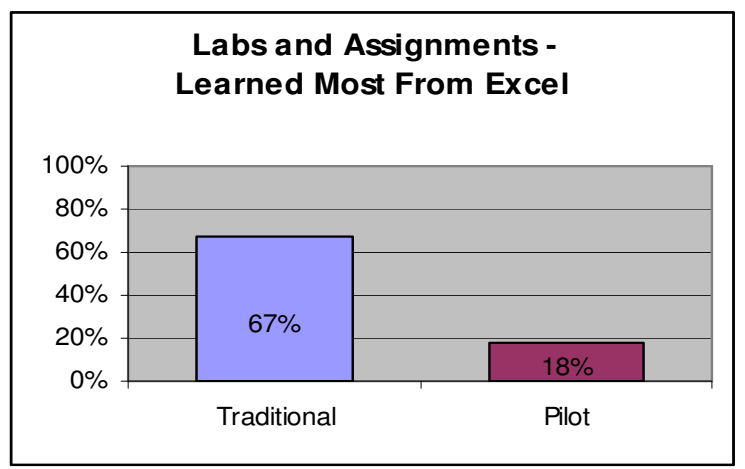

Figure 3. Students Identified Excel Activities as the Items from which They Learned the Most.

When asked if a lab day would add value (Figures 4 and 5), most students experiencing the lab during the pilot felt it would add value, while those not experiencing it in the traditional section were less convinced. Respondents in all three sections stated they were unsure of the value of a lab $(13 \%$ in traditional, $9 \%$ in pilot); however, no one in the pilot stated the lab did not add value.

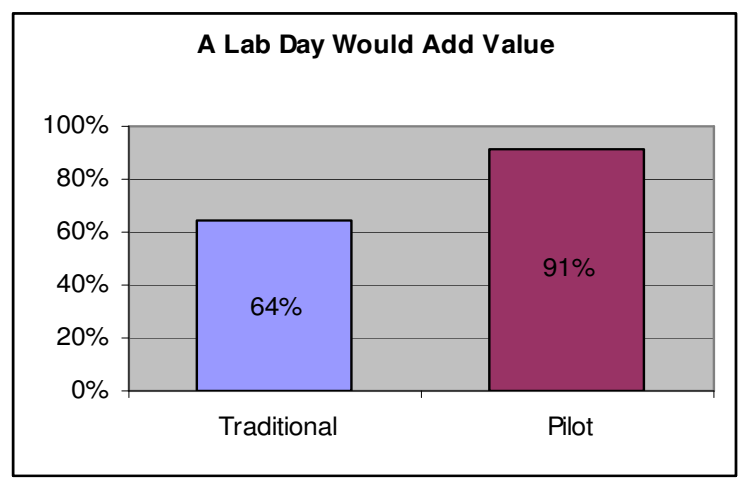

Figure 4. The inclusion of a Lab Session each Week Would add Value to the Course.

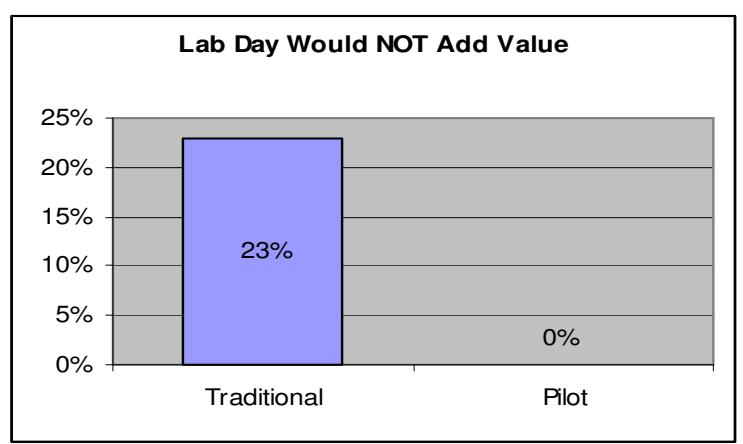

Figure 5. Students who did not believe a lab session would add value to the course.

To understand the level of learning during the course labs and assignments, Thomson/Course Technology MS Excel pre- and post-tests demonstrated a competency increase of $25 \%$ for those students with valid pre and post-test scores. The level of learning measured by the test was lower than expected, as students were successful in completing a series of tutorials and case studies using the skills throughout the course.

Factors that may impact the results of the tests include technology issues experienced by as many as half of the students during the tests; the inability for students to demonstrate their actual knowledge in the simulated environment; and lack of student motivation, as they were graded on completing the assessment and not on their level of improvement. In the future, the intention is to include a grade based on the level of achievement.

After completion of the pre-test in the first week of class, students were required to complete a series of Excel tutorials during the lab sessions. Once a base level of skill was developed, three case assignments were provided to reinforce student learning in a simulated business scenario. The same storyline (Row-Mance Yachts) was used throughout these Excel cases, as well as during additional lab activities. Student comments regarding this approach included: "The on-going Row-Mance labs taught the most..." and "I like picking out the computers. Actually, I liked all of the projects with the fictitious company. They were well thought out and very practical in terms of bringing the theory into a realworld setting."

Numerous students demonstrated their support for the case activities and the storyline, but mentioned the activities needed to be better designed. Many added their understanding that this was the first "trial" and acknowledged the activities should improve based on learnings over time. 
To facilitate the labs during the pilot, three senior IS students played the role of lab instructors. With the small pilot, this would not be necessary; however, moving the concepts into mainstream require additional support, as the lead core IS course instructor can have over 240 students in two large sections each semester. As a result, hands-on labs with less than 30 students each, allowing for individual mentoring and support, are not practical for one instructor to facilitate. The senior IS students have been identified as an option to provide this support, and having three seniors participate in the pilot generated the following recommendations:

- A back-up activity or "Plan B" must be developed and available for each week-a software application that was the basis for an entire lab did not work properly, and with the focus on making the original activity a success, there was no alternative activity on which to fall back.

- A lead should be identified to develop and facilitate each activity, with someone else "oncall." One person needs to be responsible for each lab, providing a central contact and one person ensuring all pieces are in place and ready to go. One senior did not follow through on pieces of activities they committed to prepare, leaving others to scramble to finish the development prior to the lab.

- All instructors need to review and test each activity - an answer key was incorrect, causing class participants to be provided with invalid feedback regarding their projects; other related activities, therefore, did not flow coherently.

Even with the challenges experienced, the support of the senior IS students was critical to providing a high-quality experience for the students. The course participants readily used the lab instructors as resources both in and out of the classroom, demonstrating the value they found in them.

\section{CONCLUSIONS}

Based on the perceptions of students in the pilot section of the core IS course, it is believed the changes implemented in the spring of 2006 are taking the course in a positive direction. A major learning is the value the lab sessions brought to the class, with $91 \%$ of the participants feeling they added value, and the remaining $9 \%$ stating they were unsure.
Based on the number of students required to take the core IS course, lab instructors are essential to the success of the pedagogical model being implemented. The ability for senior IS students to further develop the skills they have obtained through their educational career-as well as practice the ability to work with those that have less knowledge in ISprovides benefits for the seniors as well as the core IS course participants who can utilize a greater level of personal support in the course.

With the small number of students impacted by the pilot course in the spring of 2006, further data will be collected and analyzed to fully understand the impacts as all core IS course students experience a lab environment facilitated by senior IS students in the fall of 2006.

Areas of additional research include the use of a student response system, IS business simulation, and other in-class activities and the relative level of engagement of students during the lecture components of the course.

\section{REFERENCES}

1. America's Career InfoNet. (2006). Fastest Growing Occupations. Retrieved 29 July 2006 from http://www.acinet.org/oview1.asp?next=ov iew1 \&Level=BAplus \&optstatus $=\&$ jobfam $=\& i d$ $=1 \&$ nodeid $=3 \&$ soc code $=\&$ stfips $=00 \& x=49 \& y=$ 14.

2. Association to Advance Collegiate Schools of Business. (2006). Eligibility Procedures and Accreditation Standards for Business Accreditation. Retrieved 28 May 2006 from http://www.aacsb.edu/accreditation/business/ST ANDARDS.pdf.

3. BizEd (2004, May 12) Are U.S. enrollments in IT shrinking? BizEd, 50-52, retrieved 29 July 2006 from www.aacsb.edu/publications/archives/mayjune0 4/p50-52.pdf.

4. Bureau of Labor Statistics. (2005). Computer Systems Design and Related Services. Retrieved 29 July 2006 from http://www.bls.gov/ oco/cg/cgs033.htm.

5. Gorgone, J.T., Davis, G.B., Valacich, J.S., Topi, H., Feinstein, D. L., Longenecker, H.E. (2002). IS 2002 Model Curriculum and Guidelines for Undergraduate Degree Programs in Information Systems. Retrieved 28 May 2006 from http://www.acm.org/education/is2002.pdf. 